ligament leads to the production of the subperitoneal variety of ectopic gestation, as described by Hart and Carter, and these authors (page 9l) claim their own observations as supporting my views. Again, your reviewer has entirely missed the point that Jessop's and Champneys' cases are the result of the secondary rupture of the broad ligament cyst into the peritoneum, a fact in the development of ectopic pregnancy that was fully established before $I$ was born. On page 59 my views on this subject are given at length, and must have escaped the eye of your reviewer, or he never could have said that my opinion is directly contrary to the evidence of these two cases, and that my book in this respect bears marks of arbitrary disregard of even the facts I quote. He further says that Dr. Herman's critical and valuable paper is "dismissed with the contemptuous remark" \&c. This is most unfair, for the conclusions of Dr. Herman's paper are given and adopted (p. 84) at full length as "practically fatal to vaginal section." A similar and almost as serious a misrepresentation occurs in the same paragraph, where it is said that " a similar sentiment occurs with regard to a paper by Dr. Champneys on Primary Laparotomy." I have indicated no such sentiment about this paper, which I quote largely as a valuable contribution. I point out that the blunder in the case was the non-performance of a second abdominal section immediately at the onset of the serious symptoms; and surely this is a perfectly legitimate criticism. If blunders are not to be pointed out, how are we to make progress? Your reviewer further says that my table of cases does not contain the evidence of tubal gestation, and that the evidence of tubal gestation being often obscure and the proof of its existence difficult, "we have therefore no independent means of judging of the value of the above statements." This is really an astonishing array of statements. The proof of tubal gestation after the tube has been removed by operation or at a postmortem examination is as easy as possible; and the preparations obtained from every one of the cases given in the tables have been exhibited, and the details published in the records of the Birmingham Medical Societies or in the Transactions of the British Gynæcological Society. The table given in my book is merely for the purpose of the authentification of the cases, the nature of which has long since been placed beyond dispute. I did not considerit any more necessary to enter into such elementary details than to state, in the table or elsewhere, that each patient had been put under an anæsthetic before I operated. When an obstetrician publishes a table of statistics of cases of labour, surely it may be assumed that in each there were indisputable grounds for asserting that the products of conception had been displayed. Similarly, when a table of cases of operation for ruptured tubal pregnancy is published, it may be assumed that in every one satisfactory evidence was obtained of the presence of a fotus and placenta, or of a placenta at least, without the necessity of a tedious recital of the fact. If it is not to be so, then medical literature, already rather a weariness to the flesh, will become a burden intolerable. If your reviewer has any honest doubt about the table or any of its details, let him make a specific challenge, and I am prepared to meet him with the specimens.

I am, Sirs, yours faithfully,

Birmingham, Jan. 21st, 1889.

LAWSON TAIT.

* * Having submitted the above letter to our reviewer, we have received the following reply:-_" I certainly thought that the 'placental' sound was an obsolete phrase, and that it was used by Mr. Tait (p. 67) as equivalent to the uterine sound or bruit. His observations on this matter are not known to me, and are apparently at variance with those of other observers. I do not understand his sentence beginning, ' He clearly does not see,' and refer him to the review (p. 128): 'The subperitoneal variety has recently been proved by frozen sections of a case described by Hart and Carter, and quoted at length, and therefore does occur.' There is, in my opinion, no evidence in either Jessop's or Champneys' case of subperitoneal development and secondary rupture. Moreover, Mr. Tait, in my opinion, disregards the evidence of cases which he quotes when he says that Mr. Jessop's case is (p. 59) 'perfectly unique,' and states that 'as a matter of fact it stands by itself, and may therefore be known as the case of intraperitoneal ectopic pregnancy.' I leave Mr. Tait to reconcile the words he uses about Dr. Herman's paper (review, p. 129) with the alleged adoption of his results. Dr. Herman (p. 84) describes certain conditions in which vaginal is to be preferred to abdominal section, and Mr. Tait not only says that the result of Dr. Herman's observations is fatal to vaginal section, but adds, 'This kind of research is really of little value,' \&c. (review, p. 129). If this is not contemptuous dismissal, Mr. Tait will perhaps describe it to his taste. As regards Dr. Champneys' paper, the words may be quoted (p. 98): "Certainly it is not a question which will be settled by the tabulation of a number of cases mostly dissimilar in the extremest degree from one another, and incapable of leading to anything but confusion when paraded in the form of statistical evidence.' 'This was his language with regard to what he now calls 'a valuable contribution.' As regards the list of operations, the details or nature of the proof of each should have been included in a work bearing the title which this work bears, and I cannot agree that the proof of tubal gestation is 'as easy as possible'; on the contrary, the identification of the placenta is often a matter of great difficulty.'

\section{THE USE OF IODOFORM IN SURGICAL PRACTICE.}

To the Editors of THE LANCET,

SIns,-Messrs. Thomas Smith and Morrant Baker, and Dr. Brandt of Christiania, have written me very kind letters respecting a case of "curious delirium resembling mania " occurring during the after-treatment of a case of suppurative peritonitis, treated by laparotomy and drainage fully reported in THE LANCET of Dec. 29th. They suggest that the delirium was caused by iodoform poisoning, which was my own view, though that was not mentioned in the very brief abstract of the case, which alone had been seen by the three gentlemen above named (who wrote before Dec. 29th). Mr. Marsh and others have spoken to me on the subject, and Dr. Street, of Westgate, has sent you an interesting letter and case.

I have been particularly asked to write to you and call attention to the danger of the signs of iodoform poisoning being overlooked or confounded with delirium or mania from other causes. Messrs. Smith, Baker, Brandt, and Marsh have all seen very striking cases. Mr. Morrant Baker also asks me to point out that the signs of poisoning do not always disappear when the drug is discontinued. Indeed, the powder cannot always be got out of the recesses in which it is placed.

As sometimes the cases do not end until the lunatic asylum or death itself is reached, the subject is very serious and important. For myself, I usually employ iodoform crystals very sparingly, and the powder not at all if the crystals are to be had. But iodoform gauze is surely an invaluable, a unique, and irreplaceable substance. I have occasionally noticed such symptoms as headache, rise of temperature, rapid pulse, and irritability fairly attributable to iodoforn used moderately, but nothing worse. In the case of laparotomy under notice, both the powder and ganze were used exceptionally freely. Two sheets of iodoform gauze, each, when open, the size of a large pocket handkerchief, were folded like closed umbrellas, and nearly half of each placed in the abdominal cavity (for reasons explained in describing the case). About half a thimbleful was placed in the bottom of the glass drain in Douglas's pouch. Moreover, the gauze was wrung out in 1 to 2000 sublimate before being used, and kept moist where it lay on the skin of the flanks (to make it act as a capillary drain). But the fact must not be ignored that the symptoms of (iodoform?) poisoning did not disappear until call antiseptics were discontinued, including boracic acid, and nothing but boiled water used. Von Mostig-Moorhof says carbolic solutions should not be used with iodoform, because the former tend to check elimination by the kidneys. Can sublimate solutions or even boracic act in the same way? I should be very sorry if my case were to deter surgeons from using the moist iodotorm gauze capillary drain in 
peritoneal suppurations. The latter are serious and mortal conditions, and ought to be treated courageously. The gauze can easily be withdrawn at any time, in which respect it differs advantageously both from powder and crystals. For moistening the gauze when used in large quantities, probably boiled water had best be used. But for all ordinary quantities sublimate solutions do very well. The gauze may be adulterated. An instance is reported in which a beautiful specimen was found to have been stained yellow with an aniline die, and to contain only just enough iodoform to make it smell. ${ }^{1}$ A very cursory examination would discover this. Lastly, there seem to be individual idiosyncrasies and weakly people; the old and (according to Dr. Brandt) the very young are specially liable to iodoform poisoning.

I am, Sirs, yours faithfully,

George-st., Hanover-sq., Jan. 14th, 1889.

C. B. KEETLEY.

\section{FOREIGN BODIES IN THE AIR PASSAGES. To the Editors of TuE LANCET.}

SIRs,-In your last issue (Jan. 19th) there appears an article on the above subject, in which it is stated that " all authorities urge the immediate performance of tracheotomy in every case where the foreign body is diagnosed as present below the larynx." It is also laid down that " after, but not before, free incision has been made into the trachea, a good inversion and succussion may be safely tried, and are especially likely to succeed if the foreign body is heavy and smooth." If the author of this article will refer to THE LANCET of Nov. 16th, 1878, p. 721 , he will find a communication from me, in which I have pointed out how this proceeding of inversion, supplemented by a suggestion of Dr. George Johnson, may, without open ing the trachea or larynx, be adopted with safety, and with a fair probability of success in the case of coins and similar bodies. It at once succeeded without anv unpleasant symptom in the case I have there narrated, in which, if the dictum urged in the article from which I have quoted had been acted upon, an unnecessary tracheotomy would have been performed; and other cases have been recorded in which this manouvre has been successful, with, no doubt, a certain amount of risk and danger in the attempt as ordinarily practised. The danger of the practice, as I have pointed out, has depended upon the mode in which it has been carried out, notably in the case of the late Mr. Brunel. The principle, and the practice founded upon it, of the plan I have adopted and advised are referred to in Erichsen's Surgery ; and by its adoption in suitable cases a serious operation may, without risk to the patient, be rendered unnecessary.

I am, Sirs, yours faithfully,

Swansea, Jan. 19th, 1889. GEORGE PADLEy.

\section{THE PROTECTION OF THE MEDICAL PROFESSION. \\ To the Editors of THE LANCET.}

Sirs,-Not until our profession makes up its mind to combine and demand our right of protection shall we get rid of our present difficulties. In pouring forth now what I consider to be our grievances, more particularly as general practitioners, and the remedies to be adopted, I will endeavour to be as brief and concise as the importance of the subject will permit.

1. By absence of unanimity and action we have allowed one-sided legislation at various times to take place, binding us down by certain laws, increasing the stringency of those laws, warning us under heavy penalties that we shall not do this, that, and the other, whilst we have shut our eyes and waited to see what would be sent us; on opening them we find ourselves fettered heavily, but with no protection whatever ourselves against the quack and the charlatan. Solicitors are well protected, and have their tariff of fees anyone entering a solicitor's office knows what fee he becomes liable for; let a notary or accountant attempt to overstep that line, which is so clearly defined, and the result is disastrous to him.

2. The practitioner is in frequent instances compelled to supply his patient, whether he requires it or not, with something tangible to take away with him as a sort of return for

1 G.R. Fowler, Ann. of Surg., Dec. 1888. his money, in order to obtain a fee, his patient not being satisfied to pay for advice; the question asked is not "What is your fee?" but "How much is the medicine?" If it is the custom of the practice to give a prescription, the patient uses it first himself, and, out of the gratitude of his heart, lends it in due course to his various friends and relatives.

3. We see constantly the evil results of the public treating their own complaints, or being treated by the druggist, or gratuitously at the out-door department of a local hospital. As regards self-dosing, which is on the increase, the profession itself is much to blame. It is no unusual thing for a patient to introduce himself with_- "Dr. Blank was giving me bromide, but latterly he tried chloroform and Indian hemp," \&c. This custom of telling the patient too much is a modern one, is most pernicious, is prolific of evil, and has its origin in the hospital. Our forefathers were certainly in this matter wiser and more discreet. The profits which ought to accrue to the practitioner, were he protected as justice demands, go into the pockets of lawless self-constituted prescribers. We practitioners rob the druggist of the dispensing which is his due, whilst he robs us of what would be the pleasantest and most profitable part of our duties-home prescribing. The local hospital is, as a general rule, a curse to the general practitioner, frequently robbing him of some of his best paying patients.

4. On the one hand, we see a few heads of the profession amassing large fortunes, raising their fees perhaps to fabulous prices to keep the public from the doorstep; whilst, on the other, we see the plodding, laborious, general practitioner, in many instances both skilful and experienced, who can scarcely "make his ends meet." The well-to-do portion of the community naturally, as legislation (free trade ?) now exists, rush at once, if ill, to head-quartersi.e., to their idea- of the leading fashionable man in town, with the consequence that the general practitioner is left to be dependent upon the poor and the artisan, his fees being kept down to ridiculously low figures by his neighbour, the intelligent druggist, who can afford to do the same work at a lower figure.

These few axioms I propound as the principal of our grievances as general practitioners. What, then, is the remedy? Some such legislation as the following:-

1. That no person, except he be a registered medical practitioner, shall prescribe in any case of illness, attempt. either to perform any surgical operation or reduce any fracture or dislocation.

2. That no prescription be dispensed by a druggist without being first signed and dated by a registered practitioner, each repetition undergoing the same ordeal.

3. That no more patents be granted for proprietary medicines.

4. That no practitioner be allowed to regularly dispense for his patients, only in cases of emergency (so worded as to. allow of his carrying a pocket-case of drugs, or keep a private selection for his own use or for emergencies)

5. That a special class of practitioners be formed, with a separate place in the Register, to be called "consultants," consisting of $(a)$ physicians and $(b)$ surgeons. That no practitioner shall assume the position of "consultant" unless he possess a university degree in medicine and surgery, as well as a fellowship from either college, according to the branch he takes up, and until he has attained the age of: thirty-five years.

6. That no "consultant" shall attend a patient professionally except he be introduced by, and the patient be under the care of, a general practitioner.

7. That special tariffs of fees be prepared for use by the two classes of practitioners-(1) for general practitioners : (2) for consultants, consisting of $(a)$ physicians $(b)$ surgeons. These suggestions may appear at first sight to border upon the impossible, but when we come to consider the immensity of the change necessitated by the measure that has just become law in this country, turning every county in England. and Wales topsy-turvy, surely we may be allowed to consider, with a view to future legislation, any system which has for its object the amelioration of a profession acknowledged to be one of the most noble, and surely not the least important, ever instituted by man; a profession at present. without any system, method, or proper government; a pro. fession apparently at the mercy of all and protected by none. It is only by the adoption of some such system as I have here roughly sketched that the discordant units which at present palm themselves off as the "medical profession" can be consolidated and made into one harmonious whole. It is only in this manner that 